\title{
A rare case of pyopneumothorax
}

\author{
Um caso raro de piopneumotórax
}

\section{To the Editor:}

Microorganisms of the genus Gemella are facultative anaerobic, catalase-negative, Grampositive cocci that are similar to Streptococcus viridans. ${ }^{(1)}$ These commensal bacteria of the oropharynx and upper airway rarely cause infections in humans. However, reports of infectious processes in different locations have been increasing in number. The species $G$. morbillorum and $G$. haemolysans are the most common pathogenic species, typically causing meningitis and endocarditis. ${ }^{(2)}$ Although the pulmonary infections caused by these bacteria are rare, they can cause lung abscesses, necrotizing pneumonia, and pleural empyema. (3) We recently treated a patient who presented with pyopneumothorax, the etiology of which was $G$. haemolysans.

The patient was a 29-year-old White male smoker (15 pack-years) who was a moderate drinker and had a personal history of fracture of the left tibia, for which he had undergone surgery 8 years prior. The patient sought treatment at the emergency room due to rightsided pleuritic chest pain for one month and, 15 days later, developed an irritating cough and dyspnea that worsened progressively, without any other accompanying symptoms. The patient also reported having undergone tooth extraction two months before the hospitalization. Upon physical examination, the patient was alert (no spatiotemporal disorientation), cooperative, and hemodynamically stable, with an $\mathrm{SpO}_{2}$ of $97 \%$ $\left(\mathrm{FiO}_{2}, 21 \%\right)$. The patient also had fever (tympanic temperature, $38^{\circ} \mathrm{C}$ ), a septic appearance, and pallor of the skin and mucosa. Pulmonary auscultation revealed diminished breath sounds throughout the right hemithorax, together with absent vocal vibrations and dullness to percussion. Analytically, we observed the following: normochromic normocytic anemia (hemoglobin, $12.6 \mathrm{~g} / \mathrm{dL})$; leukocytosis $(15,380$ cells $/ \mathrm{mL})$ with neutrophilia (77.1\%); ESR, $103 \mathrm{~mm} / \mathrm{h}$; C-reactive protein, $358 \mathrm{mg} / \mathrm{dL}$; blood urea nitrogen, $26 \mathrm{mg} /$ $\mathrm{dL}$; creatinine, $0.6 \mathrm{mg} / \mathrm{dL}$; negative serology for HIV-1, HIV-2, HBV, and HCV; negative blood cultures; and negative results for Mycobacterium tuberculosis in sputum. A chest X-ray revealed hypotransparency in the lower thirds of the right hemithorax, with an air-fluid level. A CT scan of the chest revealed a massive collection with an air-fluid level occupying nearly all of the right hemithorax, resulting in compression of the adjacent lung parenchyma, sparing only the right upper lobe. A diagnostic thoracentesis was performed, and $15 \mathrm{~cm}^{3}$ of purulent, foulsmelling fluid were drained. A $28-\mathrm{F}$ chest tube was placed into the right seventh intercostal space on the midaxillary line. The tube remained in place for 18 days, and a total of $4,000 \mathrm{~cm}^{3}$ of purulent fluid were drained. G. haemolysans was isolated from the pleural fluid. The pleural fluid tested negative for $M$. tuberculosis. The patient received $4.5 \mathrm{~g}$ of piperacillin/tazobactam every $6 \mathrm{~h}$ for four weeks and $160 \mathrm{mg}$ of gentamicin every $24 \mathrm{~h}$ for 5 days, as well as kinetic respiratory therapy. Progressive clinical and radiological improvement was observed. The patient was discharged but was instructed to continue the respiratory therapy. He was also referred to a pulmonology clinic for outpatient treatment. In the follow-up visit, a new chest X-ray revealed significant improvement. The patient also underwent pulmonary function testing, and the results were normal.

In a review conducted in $2008,{ }^{(3)}$ only two cases of empyema due to $G$. haemolysans were identified, and both of the patients involved had presented with a history of carcinoma. The predisposing factors for $G$. haemolysans infection include poor oral hygiene and previous dental manipulation, which, due to injury to the oral mucosa, can facilitate the hematogenous dissemination of the microorganism, as well as microaspiration of oropharyngeal contents, which can facilitate bronchogenic dissemination. There is limited information regarding the sensitivity of these microorganisms to antibiotics; they are commonly sensitive to beta-lactam antibiotics and aminoglycosides, ${ }^{(3-5)}$ although cases of resistance have been described. ${ }^{(6)}$ Regarding 
the duration of the treatment, a period of at least four weeks-or until the empyema has been completely drained-is recommended. (3-5) Although $G$. haemolysans infection is a rare condition, it should be considered in immunocompromised patients or in those who have recently undergone dental procedures or gastrointestinal manipulation.

\section{Vanda Areias}

Intern, Department of Pulmonology, Faro Hospital, Faro, Portugal

\section{Jose Romero}

Attending Physician, Department of Pulmonology, Faro Hospital, Faro, Portugal

lsabel Ruivo Attending Physician, Department of Pulmonology, Faro Hospital, Faro, Portugal

Ulisses Brito

Director, Department of Pulmonology, Faro Hospital, Faro, Portugal

\section{References}

1. Woo PC, Lau SK, Fung AM, Chiu SK, Yung RW, Yuen KY. Gemella bacteraemia characterised by $16 \mathrm{~S}$ ribosomal RNA gene sequencing. J Clin Pathol. 2003;56(9):690-3.

2. Frésard A, Michel VP, Rueda X, Aubert G, Dorche G, Lucht F. Gemella haemolysans endocarditis. Clin Infect Dis. 1993;16(4):586-7.

3. Senent C, Sancho JN, Chiner E, Signes-Costa J, Camarasa A, Andreu AL. Pleural empyema caused by Gemella species: a rare condition [Article in Spanish]. Arch Bronconeumol. 2008;44(10):574-7.

4. Hayashi Y, lto G. A case of bacterial empyema caused by Gemella morbillorum [Article in Japanese]. Kansenshogaku Zasshi. 1996;70(3):259-63.

5. Veziris N, Fuhrman C, Chouaid C, Marque E, Housset B, Lange J, et al. Empyema of the thorax due to Gemella haemolysans. J Infect. 1999;39(3):245-6.

6. Kofteridis DP, Anastasopoulos T, Panagiotakis S, Kontopodis E, Samonis G. Endocarditis caused by Gemella morbillorum resistant to beta-lactams and aminoglycosides. Scand J Infect Dis. 2006;38(1112):1125-7. 